\title{
Expression of TIMP-2 in HPV-16 infected oral squamous cell carcinoma in patients in Iraq
}

\author{
Habib A Manall', Habib A Huda², Hussain A Israa', Karima Al-Salihi ${ }^{3}$ \\ 'University of Baghdad, Baghdad College of Medicine, Department of Pathology, Iraq \\ 2University of Baghdad, Al-Kindy College of Medicine, Department of Community, Iraq \\ ${ }^{3}$ The University of Nottingham, School of Veterinary Medicine and Science, Loughborough, Leicestershire, UK
}

Received for publication: April 13, 2016 Accepted: July 07, 2016

Correspondence to: Karima Al-Salihi.

The University of Nottingham, School of Veterinary Medicine and Science, College Road, Sutton Bonington, Loughborough, Leicestershire - LE12 5RD UK

E-mail: Kareema.Nasrullah@nottingham.ac.uk; kama_akool18@yahoo.co.uk; mrvsa59@gmail.com

\begin{abstract}
Aim: To determine the expression of tissue inhibitors of metalloproteinases (TIMP-2) in oral squamous cell carcinoma (OSCC) and the difference in its expression level between positive and negative HPV-16 (human papilloma virus- 16) OSCC patients. Methods: This study was conducted on 33 biopsies obtained from patients with OSCC and 10 normal oral mucosa as controls. In situ hybridization (ISH) was used to investigate the presence of HPV-16, while immunohistochemistry $(\mathrm{IHC})$ was used to estimate the expression level of TIMP-2. Results: The TIMP-2 was expressed in $27(81.8 \%)$ of OSCC sections with no significant difference between its expression level in HPV-16 positive and HPV-16 negative OSCC cases ( $p=0.058)$. TIMP-2 was found to be highly expressed in OSCC sections, and the presence of HPV was not related to its overexpression. Conclusions: The percentage of samples that appeared to accommodate detectable HPV-16 was high, but no significant difference was observed in relation to TIMP-2 expression level. Future studies with a larger number of patients are highly recommended to address the possible association between TIMp-2 and OSCC positive HPV-16.
\end{abstract}

Keywords: TIMP-2. HPV. Iraq. Oral cancer.

\section{Introduction}

The major neoplasm worldwide is oral cancer. It is accompanied with high death rate, which is associated with a routine late discovery in its development. The recurrence is a serious prognostic influence in patients with oral squamous cell carcinoma (OSCC) $)^{1-3}$. According to data from the American Oral Cancer Foundation published in 2014, over 640,000 new cases are found every year ${ }^{4}$, whereas there were 128,000 deaths due to oral cancer worldwide in 2008 according to the International Agency for Research on Cancer (IARC) $)^{5,6}$.

In Iraq, cancer made up 10\% of total deaths of all ages. Oral cancer constituted approximately $4.5 \%$ of all cancer cases and OSCC represents about $91.5 \%$ of all oral cancer and $37 \%$ of head and neck cancer according to Iraqi cancer registry ${ }^{7}$. The prevalence of oral cancer during 2003-2006 in Iraqi governorates in relation to sex, age and site has been estimated, and the study found that the highest prevalence (55.81\%) was observed in tongue, while the lowest (3.87\%) was found in the floor

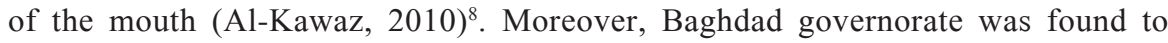
have the highest prevalence of OSCC $(41.08 \%)^{8}$. Mohammed et al. $(2015)^{9}$, detected human herpesvirus- 1 antigen in OSCC and apparently healthy control in Iraq. The detection of HHV-1 antigen, chemicals and radiation, found to play important role in the development of oral cancers in Iraq. 
Epidemiological and molecular studies have determined that the persistence of infection with high-risk human papillomaviruses (HR-HPVs) types is the most common risk factor for the development of head and neck malignancies ${ }^{10-12}$. HPVs are small non-enveloped, double-stranded, circular DNA viruses that encode two viral oncoproteins, E6 and E7. The best-characteristic properties of E6 and E7 proteins from HR-HPVs are their ability to mediate the degradation of $\mathrm{p} 53$ and $\mathrm{pRb}$, respectively. These viral proteins also interact with other several cellular factors and lead to revoke normal cell cycle checkpoint stand cell death mechanisms ${ }^{13}$. A possible malignant disorder is the proliferative verrucous leukoplakia (PVL), which is often undergone malignant transformation to $\mathrm{OSCC}^{14,15}$. Akrish et al., (2014) ${ }^{16}$ reported and compared the histologic, immunohistochemical and clinical features as well as the survival rates of carcinoma arising in patients with PVL (p-scca) and conventional squamous cell carcinoma (c-scca). The authors found that P-scca revealed considerably better prognostic factors and limited survival rates and longer duration of disease in compare to c-scca. They also suggested that p-scca may show a distinct entity, which may have clinical implications on treatment ${ }^{16}$.

Development of most solid tumors is characterized by an increase in secretion and activation of matrix metalloproteinases (MMPs) produced by either the tumor cells or tumor-associated fibroblasts. These proteins play a master role in diverse physiological processes and diseases such as the homeostatic tissue remodeling and cancer $^{17}$. Proteolytic activity of MMPs can be regulated at different levels including gene expression, protein compartmentalization zymogen to active enzyme conversion and the presence of specific inhibitors ${ }^{18}$.

Tissue or extracellular MMPs are regulated by endogenous inhibitors named tissue inhibitor metalloproteinase family 1 to 4 (TIMP-1-4). Among them, TIMP-2 is unique because it may function both as an MMP activator and inhibitor ${ }^{17}$. Although TIMPs are known to act as inhibitors of MMPs, they exhibit other biological functions. Indeed, TIMPs play complex divergent roles in metastasis, functioning both as anti-invasive agents and as prognostic indicators. Another study suggested that the overexpression of TIMPs is correlated with poor outcome in colorectal and breast carcinomas ${ }^{18}$.

In OSCC, MMP-9 and TIMP-2 expressions have shown a predictive value for tumor metastases and cause-specific survival. As in other tissue carcinomas, high expression of TIMP-2 is the most independent factor for worse prognosis in early-stage oral SCC $\mathrm{SC}^{10,12,17}$. However, expression of TIMP-2 (MMP) in HPV-16 infected OSCC patients is still incomplete and needs further investigations ${ }^{14}$, whereas, the reliable markers for progression of high-risk HPVinfected epithelium to malignancy are not yet available ${ }^{19}$. Chandolia et al., (2016) ${ }^{20}$ also approved that OSCC shows higher MMP-9 expression as compared to oral epithelial dysplasia followed by epithelium from normal oral mucosa. However, no correlation was found between the histological grades of OSCC.

A previous immunohistochemical study reported the presence of HPV type 16 infected patients with OSCC in Iraq ${ }^{21}$. Overexpression of p53 tumor suppressor gene showed significant prevalence of high oncogenic HPV genotypes in patients with OSCC in Iraq. They found herald marks for the spread of HPV among Iraqi general population, which played an important role in oral carcinogenesis ${ }^{21}$. The expressions of p53 and its related gene
MDM4 in oral, laryngeal and cutaneous squamous cell carcinoma have also been investigated using tissue microarray in $\operatorname{Iraq}^{22}$. It was found that p53 and MDM4 were frequently overexpressed in SCC cases with significant correlation between these markers, which was considered as an indicator for prognostic factor in regard to tumor grading $^{22}$. Several molecular markers have been suggested as reliable prognostic cancer biomarkers for the classification of $\mathrm{OSCC}^{19,21-26}$.

Considering all the previous facts regarding OSSC in Iraq, this study intended to investigate the expression of TIMP-2, and the difference in its expression level between positive and negative HPV-16 OSCC cases.

\section{Material and methods}

\section{Sample collection}

The study was conducted on 33 retrospective cases of OSSC taken from the Maxillofacial Center in Surgical Specialty Hospital in Baghdad between 2007 and 2009. The age of patients ranged between 30 and 95 years. None of the cases had received radiotherapy or chemotherapy. As negative controls, ten normal oral tissues, were obtained from a buccal mucosa of individuals underwent plastic surgery at the same hospital. This study was approved by the Ethical Committee / College of the Medicine/ University of Baghdad (No.2012, 11-12 Ar). The expression of HPV-16 and TIMP-2 were investigated using In situ hybridization (ISH) and immunohistochemistry (IHC) respectively.

\section{Immunohistochemistry}

Fixed paraffin tumor and control tissues were sectioned into $5 \mu \mathrm{m}$ thickness and stained according to the TIMP-2 kit manufacture's protocol (Chemicon International, USA). The slides were placed in $10 \mathrm{mM}$ citric acid buffer at $\mathrm{pH} 6.0$ and underwent antigen retrieval for $10 \mathrm{~min}$ at $680 \mathrm{~W}$ in a microwave oven. Mouse monoclonal antibody against TIMP-2 in $5 \mathrm{Ug} / \mathrm{ml}$ (Chemicon International, USA) was then added and kept overnight at room temperature. After application of peroxidase labeled secondary antibody and the DAB, the sections were finally counterstained and mounted. About 10 representative areas containing 100 SCC cells were analyzed. Immunostaining was scored using combined quantitative (percentage of tumor cells with immunoreactivity) and qualitative criteria (intensity of staining: none, weak, or strong). These parameters were then combined as: $0=$ no staining; $1=$ weak ( $<10 \%$ of tumor cells); $2=$ weak $(\geq 10 \%$ of tumor cells), and $3=$ strong $(\geq 10 \% \text { of tumor cells })^{27}$. Paraffin-embedded sections of colon cancer were immunostained as positive control.

\section{In Situ Hybridization (ISH)}

ISH procedure was done using DNA probe Hybridization/ detection System in Situ Kit (Maxim Biotech, USA), according to manufacturer's protocol. The biotinylated cDNA probe for HPV16 (Maxim biotech, USA) was diluted to $7 \%(0.7 \mu \mathrm{L}$ of the probe diluted in $9.3 \mu \mathrm{L}$ of hybridization solution). Positive control was made with housekeeping gene probe, while the negative control made with hybridization solution without probe. Determination of positive reaction was made with nuclear and/or cytoplasmic blue staining of cells ${ }^{28}$. 


\section{Statistical Analysis}

Statistical analysis of observed data was performed by utilizing SPSS 22.0 (SPSS Inc., Chicago, IL, USA) with the application of Chi-Square and Fisher Exact tests.

\section{Results}

The median age of the patients was 55 years with a mean \pm S. D. of $54.5 \pm 12.9$ years. Twenty-five of patients were males (75.8\%) and eight $(24.2 \%)$ were females. The majority of cases $(27,81.8 \%)$ were of stage 4 (according to TNM staging system); 4 cases $(12.1 \%)$ were stage 2 and 2 cases were stage $1(6.1 \%)$. The grades (using Border's system) of the tumor were as follows: low, 4 (12.1\%); intermediate, 26 (78.8\%) and high, 3 (9.1\%). Lymph nodes involvements were positive in $23(85.2 \%)$ cases.

Nuclear hybridization signals for HPV-16 were observed in $24(72.7 \%)$ of OSCC paraffin-embedded tissues, while $6(18.2 \%)$ cases appeared negative (Table 1). No detectable signals were seen in the sections from the control group. The immunoreactivity of TIMP-2 observed in 24 (72.7\%) and $3(9.1 \%)$ of positive and negative HPV-16 OSCC cases, respectively (Table 1). Immunoreactivity to TIMP-2 was localized mainly on the cell membrane and the cytoplasm of tumor cells (Figure 1. A, B). It was also detected on some stromal cells surrounding the tumor cells. No detectable signals were observed in the sections from the control group (Figure 2). The total expression of TIMP-2 was detected in $27(81.8 \%)$ of OSCC cases (Table 1) and its expression scores are illustrated in Table 2. There was no significant difference in TIMP2 expression between HPV-16 infected and non-infected cases $(p=0.058)$. In addition, the expression score of TIMP-2 revealed no significant difference between cases with and without lymph node metastases, $p=0.176$ (Table 3 ), whereas, its expression showed no significant difference considering the tumor grade and stage, $p=0.838$ and $p=0.169$, respectively (Table 4 ).

\section{Discussion}

According to a recent review article ${ }^{6}$, there are shortage in the studies regarding the correlation between OSCC, detection of HPV and expression of strictly related tumor markers. However, published articles have shown that high oncogenic HPV genotypes have an essential etiologic role in the development of OSCC worldwide $^{17,28-36}$.

The correlation between HPV and OSCC was first suggested by Syrjänen et al., (1983) $)^{14}$, who detected koilocytotic atypias in malignant oral lesions by optical microscopy and the presence of viral DNA by means of $\mathrm{ISH}^{14}$

The current study revealed positive nuclear hybridization signals for HPV-16 in 24 (72.7\%) of OSCC cases. This result is in accordance with those of previous studies, which reported a similar detection rate among HNSCC tumors with $90 \%$ of the HPV types identified as HPV-16 $6^{34,35}$. A previous study also confirmed that oral infection with HPV increased the risk of tumorigenesis of oropharyngeal cancer independent of tobacco use ${ }^{35}$. The result of the present study is also in agreement with a previous study in Iraq, which reported the significant prevalence of high oncogenic HPV genotypes in OSCC patients ${ }^{21}$.

The high-risk HPV adopts mechanism to generate the malignant progression of previously benign lesions. Earlier investigations have proved that high-risk HPVs and the two HPV-related oncoproteins E6 and E7 can immortalize and transform oral keratinocytes in vitro ${ }^{34,35}$. Pérez-Sayáns García et al. (2012) 32 $^{32}$ stated that "the expression of TIMPs in OSCC is higher in tumors than in normal tissue, which correlates with an increase of metastatic risk and regional lymph node affectation". However, the role of TIMP-2 in cervical carcinoma has been approved to be down-regulated by acute expression of HPV oncoproteins that may favor deregulated MMP activity in the context of HPV infection ${ }^{15,30}$.
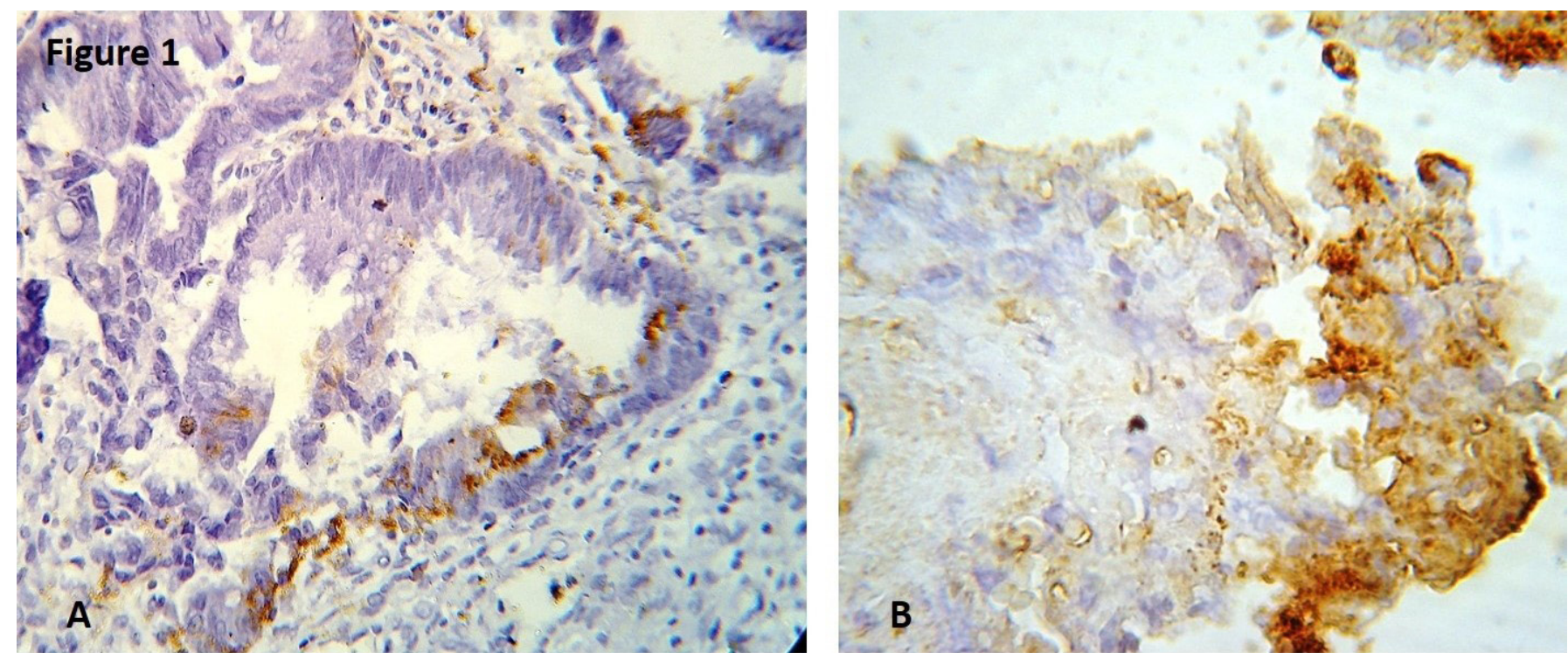

Fig.1. Immunohistochemical expression of TIMP-2 in A: colon cancer (positive control), B: OSCC Brown cytoplasmic granular staining in poor differentiated oral squamous cell cancer, strong immunostaining (score 3), (X 200). 


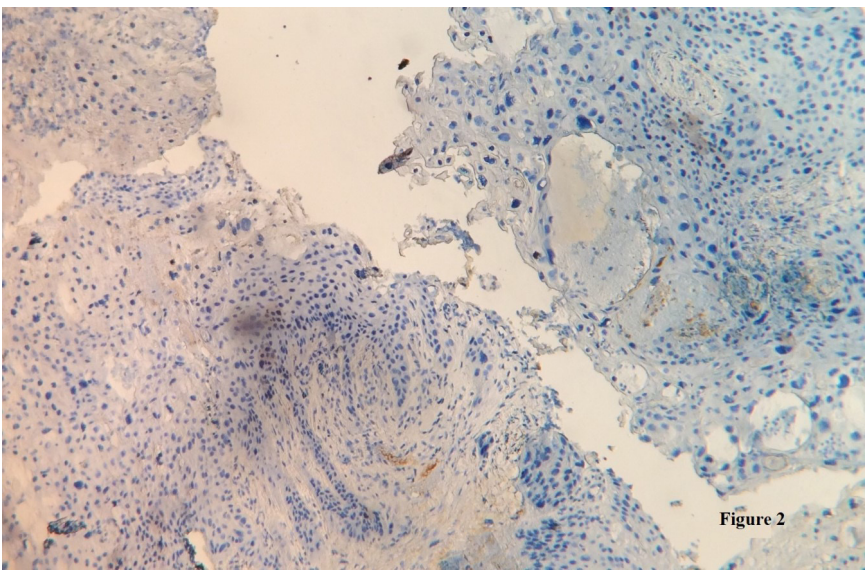

Fig.2. Immunohistochemical expression of TIMP-2 / OSCC negative control.

Table 1 - Expression of TIMP-2 in HPV-16 positive versus HPV16 negative OSCC cases $(\mathrm{p}=0.058)$.

\begin{tabular}{l|ccc}
\hline \multirow{2}{*}{ HPV } & \multicolumn{3}{|c}{ TIMP-2 } \\
\cline { 2 - 4 } & & Positive & Negative \\
& Positive & $24(72.7 \%)$ & $3(9.1 \%)$ \\
& Negative & $3(9.1 \%)$ & $3(9.1 \%)$ \\
& Total & $27(81.8 \%)$ & $6(18.2 \%)$ \\
\hline
\end{tabular}

Table 2 - Expression score of TIMP-2 in OSCC.

\begin{tabular}{llll}
\hline TIMP-2 & & & \\
Score 0 & Score 1 & Score 2 & Score 3 \\
$6(18,20 \%)$ & $12(36.40 \%)$ & $11(33.30 \%)$ & $4(12.1 \%)$ \\
\hline
\end{tabular}

Table 3 - Association of TIMP-2 expression score and lymph node metastases in OSCC $(p=0.176)$.

\begin{tabular}{l|llll}
\hline \multirow{2}{*}{ Lymph node involvement } & \multicolumn{4}{|c}{ TIMP-2 Score } \\
\cline { 2 - 5 } Positive & Score 1 & Score 2 & Score 3 & Total \\
Negative & $8(34.80 \%)$ & $12(36.40 \%)$ & $3(13.00 \%)$ & $23(85.20 \%)$ \\
\hline Total & $3(75.00 \%)$ & $0 \%$ & $1(25.00 \%)$ & $4(14.80 \%)$ \\
\hline
\end{tabular}

Table 4 - Association of TIMP-2 expression with grade and stage of OSCC $(* p=0.838, * * p=0.169)$.

\begin{tabular}{l|ccc}
\hline \multirow{2}{*}{ Grade* } & \multicolumn{3}{|c}{ TIMP-2 } \\
\cline { 2 - 4 } & Positive & Negative & Total \\
Low & $\mathbf{N}(\%)$ & $\mathbf{N}(\%)$ & $\mathbf{N}(\%)$ \\
Intermediate & $3(75)$ & $1(25)$ & $4(12.1)$ \\
High & $21(80.8)$ & $5(19.2)$ & $26(78.8)$ \\
\hline Total & $3(100)$ & 0 & $3(9.1)$ \\
\hline Stage* & $27(81.8)$ & $6(18.2)$ & 33 \\
\hline Stage I & & & \\
Stage II & $2(100)$ & 0 & $2(6.1)$ \\
Stage IV & $2(50)$ & $2(50)$ & $4(12.1)$ \\
\hline Total & $23(85.2)$ & $4(14.8)$ & $27(81.8)$ \\
\hline
\end{tabular}

In this study, immunoreactivity to TIMP-2 was observed in 27 $(81.8 \%)$ of OSCC cases. This result is in accordance with previous studies, and reflect a pathological role of TIMP-2 in OSCC ${ }^{17,18,36-}$ 39. The finding of increased TIMP-2 expression in oral cancer might be explained by the growth-promoting activity of TIMPs on a variety of cell types, or the induction of TIMPs by secreted MMPs from tumor-host interaction in the extracellular milieu ${ }^{39}$.

In addition, many immunohistochemical studies addressed the positive role for TIMP-2 in tumor progression and metastasis $^{3,16,18,21-23,26}$. It is believed that TIMP-2 suppresses the tumor invasion and metastases by inhibiting MMP-2. High activation of MMP-2 in OSCC has been reported to be associated with high expression of TIMP-2 in tumor cells ${ }^{26,39,40}$ TIMP-2 over-expression has been linked with local tumor invasion, nodal status and clinical stage, as well as with disease-free survival in oral cancer, especially in tongue $\mathrm{SCC}^{41}$.

In this study, $72.7 \%$ of OSCC appeared to harbor detectable HPV-16, whereas, no significant difference was observed in relation between positive HPV-16 and TIMP-2 expression level. However, the $p$ value was borderline $(p=0.058)$. The results of this study also revealed no significant association between level of TIMP-2 expression and tumor stage, tumor grade or lymph node metastases. However, many other researchers found significant relationships, and such studies include the following correlations between: A) the expression of TIMP-2 and tumor size or lymphatic metastasis 9,41 . B) the expression of TIMP-1 and lymphatic metastasis ${ }^{9,41,42} ; \mathrm{C}$ ) the expression of MMP-2 and histologic grade or lymphatic metastasis ${ }^{4,14,39,42-45}$.

In conclusion, this study investigated the expression of TIMP2 in HPV-16 infected tumor tissues of OSCC in Iraq, and found that the percentage of samples that appeared to accommodate detectable HPV-16 reached up to $72.7 \%$. However, no significant difference was observed in relation to TIMP-2 expression level. Future studies with a larger number of patients are highly recommended to address the possible association between TIMp-2 and OSCC positive HPV-16.

\section{References}

1. Wang B, Zhang S, Yue K, Wang XD. The recurrence and survival of oral squamous cell carcinoma: a report of 275 cases. Chin J Cancer. 2013 Nov;32(11):614-8. doi: 10.5732/cjc.012.10219.

2. Scully $C$, Kirby J. Statement on mouth cancer diagnosis and prevention. Br Dent J. 2014 Jan;216(1):37-8. doi: 10.1038/sj.bdj.2013.1235

3. Sasahira T, Kurihara M, Nishiguchi Y, Fujiwara R, Kirita T, Kuniyasu H. NEDD 4 binding protein 2-like 1 promotes cancer cell invasion in oral squamous cell carcinoma. Virchows Archiv. 2016 Aug;469(2):163-72. doi: 10.1007/s00428-016-1955-4.

4. Oral Cancer Foundation. Oral Cancer Facts. The Oral Cancer Foundation. Available from: http://www.oralcancerfoundation.org/facts.

5. Jemal A, Bray F, Center MM, Ferlay J, Ward E, Forman D. Global cancer statistics. CA Cancer J Clin. 2011 Mar-Apr;61(2):69-90. doi: 10.3322/ caac. 20107

6. Lima MAP, Silva CGL, Rabenhorst SHB. Association between human papillomavirus (HPV) and the oral squamous cell carcinoma: a systematic review. J Bras Patol Med Lab. 2014 Feb [cited 2014 
Apr];50(1):75-84. Available from: http://www.scielo.br/pdf/jbpml/ v50n1/1676-2444-jbpml-50-01-0075.pdf.

7. Iraq. World Health Organization - Noncommunicable Diseases (NCD) Country Profiles, 2014.

8. Al-Kawaz AB (2010). Oral squamous cell carcinoma in Iraq: clinical analysis. MDJ. 2010;7(1):100-5.

9. Mohammed NA, Hussein AA, Majeed AH. Detection of Human Herpesvirus Type-1 Antigen in Tissues of Oral Squamous Cell Carcinoma by Direct Immunofluorecent Assay. Diyala J Med. 2015 Jun;8(2):38-45.

10. Mork J, Lie AK, Glattre E, Hallmans G, Jellum E, Koskela P, et al. Human papillomavirus infection as a risk factor for squamous-cell carcinoma of the head and neck. N Engl J Med. 2001 Apr 12;344(15):1125-31.

11. Nishioka S, Fukushima K, Nishizaki K, Gunduz M, Tominaga S, Fukazawa $\mathrm{M}$, et al. Human papillomavirus as a risk factor for head and neck cancers: a case-control study. Acta Otolaryngol. Suppl. 1999;540:77-80.

12. Oda $D$, Bigler L, Lee $P$, Blanton R. HPV immortalization of human oral epithelial cells: a model for carcinogenesis. Exp Cell Res. $1996 \mathrm{Jul}$ 10;226(1):164-9.

13. Miller CS, Johnstone BM. Is oral infection with human papillomavirus (HPV) a risk factor for oral squamous cell carcinoma (OSCC)? EvidenceBased Dent. 2003 Jun 28;4(2):29. doi:10.1038/sj.ebd.6400171.

14. Syrjanen K, Syrjanen S, Lamberg M, Pyrhonen S, Nuutinen J. Morphological and immunohistochemical evidence suggesting human papillomavirus (HPV) involvement in oral squamous cell carcinogenesis. Int J Oral Surg. 1983 Dec;12(6):418-24.

15. Moberg M, Gustavsson I, Gyllensten U. Real-time PCR-based system for simultaneous quantification of human papillomavirus types associated with high risk of cervical cancer. J Clin Microbiol. 2003 Jul;41(7):3221-8.

16. Akrish S, Ben-Izhak O, Sabo E, Rachmiel A. Oral squamous cell carcinoma associated with proliferative verrucous leukoplakia compared with conventional squamous cell carcinoma--a clinical, histologic and immunohistochemical study. Oral Surg Oral Med Oral Pathol Oral Radiol. 2015 Mar;119(3):318-25. doi: 10.1016/j.0000.2014.10.023.

17. Stetler-Stevenson WG. The tumor microenvironment: regulation by MMP-independent effects of tissue inhibitor of metalloproteinases-2. Cancer Metastasis Rev, 2008 Mar;27(1):57-66.

18. Görögh T, Beier U H, Bäumken J, Meyer JE, Hoffmann M, Gottschlich $S$, et al. Metalloproteinases and their inhibitors: influence on tumor invasiveness and metastasis formation in head and neck squamous cell carcinomas. Head Neck. 2006 Jan;28:31-9.

19. Gillison ML. Human papillomavirus and prognosis of oropharyngeal squamous cell carcinoma: implications for clinical research in head and neck cancers. J Clin Oncol. 2006 Dec;24(36):5623-5.

20. Chandolia B, Basu SK, Kumar M. Can MMP-9 be a Prognosticator Marker for Oral Squamous Cell Carcinoma? J Clin Diagn Res. 2016 Jan;10(1):ZC09-13. doi: 10.7860/JCDR/2016/14128.7034.

21. Ali SHM, Al-Hijazi AY, Khashman BM (2011). P53-tumor suppressor gene overexpression in huma papilloma virus-infected patients with oral squamous cell carcinoma. J Bagh College Dentistry. 2011;23 (Spec Issue):70-6.

22. Jabar S, Sarkis S, Madjd Z, Kalantari E. The expression of p53 and mdm4 in oral, laryngeal and cutaneous squamous cell carcinoma; a comparative study by tissue microarray. Eur Scientif J, 2013 Dec;9(36):56-73.

23. Katayama A, Bandoh N, Kishibe K, Takahara M, Ogino T, Nonaka S, et al. Expressions of matrix metalloproteinases in early-stage oral squamous cell carcinoma as predictive indicators for tumor metastases and prognosis. Clin Cancer Res. 2004 Jan 15;10(2):634-40.

24. Lee SY, Park SY, Kim SH, Choi EC. Expression of matrix metalloproteinases and their inhibitors in squamous cell carcinoma of the tonsil and their clinical significance. Clin Exp Otorhinolaryngol. 2011 Jun;4(2):88-94.

25. Al-Salihi KA, Ang SL, Azlina A, Farini MS, Jaffar H. Immunohistochemical and molecular genetic analysis of $p 53$ in oral squamous cell carcinoma (scc) in Hospital University Science Malaysia: a preliminary study. Braz J Oral Sci. 2008 Jan-Mar;7(24):1476-83.

26. Mashhadiabbas F, Mahjour F, Mahjour SB, Fereidooni F, Hosseini FS. The immunohistochemical characterization of MMP-2, MMP-10, TIMP-1, TIMP-2, and podoplanin in oral squamous cell carcinoma. Oral Surg Oral Med Oral Pathol Oral Radiol. 2012 Aug;114(2):240-50. doi: 10.1016/j.0000.2012.04.009.

27. Maheshwari V, Sharma SC, Narula V, Verma S, Jain A, Alam K. Prognostic and predictive impact of Ki67 in premalignant and malignant squamous cell lesion of oral cavity. Int J Head Neck Surg. 2013 MayAug;4(2):61-5.

28. Ree AH, Florenes VA, Berg JP, Maelandsmo GM, Nesland JM, Fodstad O. High levels of messenger RNAs for tissue inhibitors of metalloproteinases (TIMP-1 and TIMP-2) in primary breast carcinomas are associated with development of distant metastases. Clin Cancer Res. 1997 Sep;3(9):1623-8.

29. Grimminger CM, Danenberg PV. Update of prognostic and predictive biomarkers in oropharyngeal squamous cell carcinoma: a review. Eur Arch Otorhinolaryngol. 2011 Jan;268(1):5-16. doi: 10.1007/s00405010-1369-x.

30. Cardeal LB, Boccardo E, Termini L, Rabachini T, Andreoli MA, di Loreto $\mathrm{C}$, et al. HPV16 oncoproteins induce mmps/reck-timp-2 imbalance in primary keratinocytes: possible implications in cervical carcinogenesis. PLoS One. 2012;7(3):e33585. doi: 10.1371/journal.pone.0033585.

31. Yoshizaki T, Maruyama $Y$, Sato $H$, Furukawa M. Expression of tissue inhibitor of matrix metalloproteinase-2 correlates with activation of matrix metalloproteinase-2 and predicts poor prognosis in tongue squamous cell carcinoma. Int J Cancer. 2001 Jan 20;95(1):44-50.

32. Pérez-Sayáns García M, Suárez-Peñaranda JM, Gayoso-Diz P, Barros-Angueira F, Gándara-Rey JM, García-García A (2012). Tissue inhibitor of metalloproteinases in oral squamous cell carcinomas - a therapeutic target? Cancer Lett. 2012 Oct 1;323(1):11-9. doi: 10.1016/j. canlet.2012.03.040.

33. Dürst M, Dzarlieva-Petrusevska RT, Boukamp P, Fusenig NE, Gissmann L. Molecular and cytogenetic analysis of immortalized human primary keratinocytes obtained after transfection with human papillomavirus type 16 DNA. Oncogene. 1987;1:(3):251-6.

34. Feller L, Wood NH, Khammissa RA, Lemmer J. Human papillomavirusmediated carcinogenesis and HPV-associated oral and oropharyngeal squamous cell carcinoma. Part 2: Human papillomavirus associated oral and oropharyngeal squamous cell carcinoma. Head Face Med.n 2010 Jul 15;6:15. doi: 10.1186/1746-160X-6-15.

35. Zhu C, Ling Y, Dong C, Zhou X, Wang F. The relationship between oral squamous cell carcinoma and human papillomavirus: a meta-analysis of a Chinese population (1994-2011). PLoS One. 2012;7(5):e36294. doi: 10.1371/journal.pone.0036294.

36. McLaughlin-Drubin ME, Münger K (2009). Oncogenic activities of human papillomaviruses. Virus Res. 2009 Aug;143(2):195-208. doi: 10.1016/j.virusres.2009.06.008. 
37. Ikebe T, Shinohara M, Takeuchi H, Beppu M, Kurahara S, Nakamura S, et al. Gelatinolytic activity of matrix metalloproteinase in tumor tissues correlates with the invasiveness of oral cancer. Clin Exp Metastasis. 1999 Jun;17(4):315-23.

38. O-charoenrat P, Rhys-Evans P, Eccles SA. Expression of matrix metalloproteinases and their inhibitors correlates with invasion and metastasis in squamous cell carcinoma of the head and neck. Arch Otolaryngol Head Neck Surg. 2001 Jul;127(7):813-20.

39. Grignon DJ, Sakr W, Toth M, Ravery V, Angulo J, Shamsa F, et al. High levels of tissue inhibitor of metalloproteinase-2 (TIMP-2) expression are associated with poor outcome in invasive bladder cancer. Cancer Res. 1996 Apr 1;56(7):1654-9.

40. Ondruschka $C$, Buhtz $P$, Motsch $C$, Freigang $B$, Schneider-Stock $\mathrm{R}$, Roessner $\mathrm{A}$, et al. Prognostic value of MMP-2, -9 and TIMP1, -2 immunoreactive protein at the invasive front in advanced head and neck squamous cell carcinomas. Pathol Res Pract. 2002;198(8):509-15.
41. Sternlicht MD, Bissell MJ, Werb Z. The matrix metalloproteinase stromelysin-1 acts as a natural mammary tumor promoter. Oncogene. 2000 Feb 21;19(8):1102-13.

42. Lee JI, Jin BH, Kim MA, Yoon HJ, Hong SP, Hong SD. Prognostic significance of CXCR-4 expression in oral squamous cell carcinoma. Oral Surg Oral Med Oral Pathol Oral Radiol Endod. 2009 May;107(5):678-84. doi: 10.1016/j.tripleo.2008.12.047.

43. Qu H, Xin ZE, Jing X. Expression and correlation of MMP-2. TIMP-2 in oral squamous cell cancer. J Hard Tissue Biol. 2005;14(2):311-2.

44. Singh RD, Haridas N, Patel JB, Shah FD, Shukla SN, Shah PM, et al. Matrix metalloproteinases and their inhibitors: correlation with invasion and metastasis in oral cancer. $2010 \mathrm{Jul} ; 25(3): 250-9$. doi: 10.1007/ s12291-010-0060-8.

45. Blancato J, Singh B, Liu A, Liao DJ, Dickson RB. Correlation of amplification and overexpression of the c-myc oncogene in high-grade breast cancer: FISH, ISH and immunohistochemical analysis. $\mathrm{Br} \mathrm{J}$ Cancer 2004 Apr 19;90(8):1612-9. 